أثر استنفدام أسلوب العصف الذهني على تعلم المهارات الأساسية في

الكرة الطائرة لدي تلاميذ المرهلة الابتندائية

• أ. د / رانيا مهمد هسن سعيد الهواريك

•" دا عمرو مصطفى السايح محمد

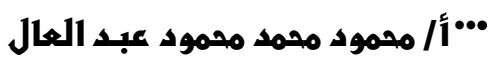

مقدمة ومشنكاة البهن:

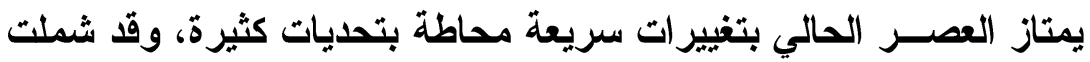

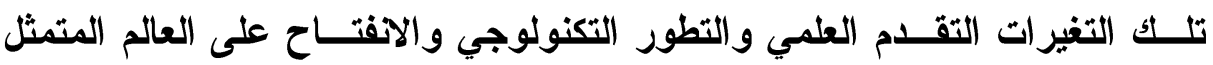

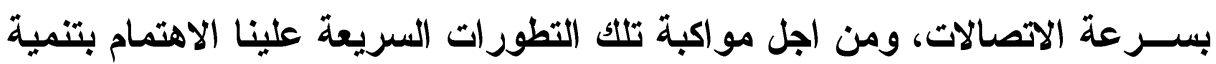
العقول المبدعة القادرة على حل المشكلات القائمة، وعلية فقد أصبح تنمية القدرات الاته

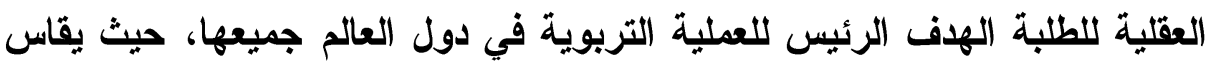
تقدم الدول بمقار قدرتها على تنمية عقول أبنائها. التي ترمي إلى مســـاعدة الطالب على تحصــــــل الأفكار و وإعطاء الأحكام والقرارات المناسبة للوصول إلى الاستنتاجات الصحيحة. (0 1 : 9 ؛)

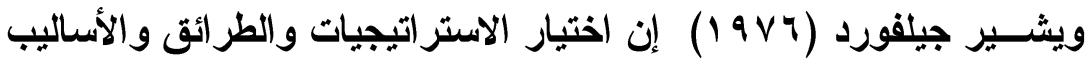

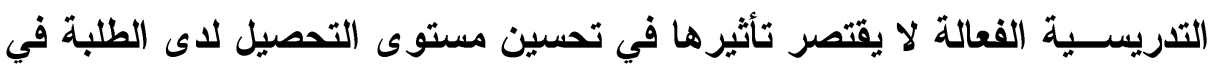

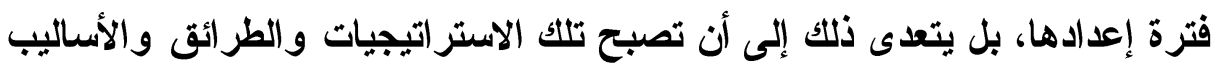

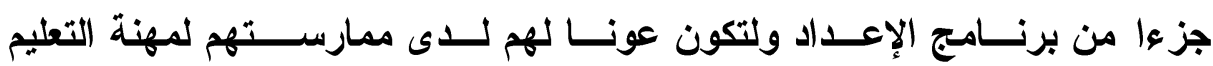

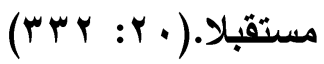

ويجب أن نشـير إلى أن المهارة في الألعاب الرياضية بصفة عامة والكرة

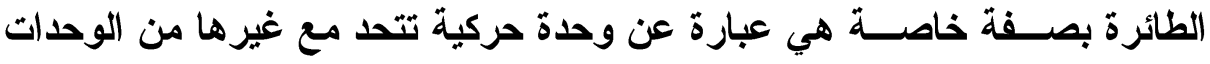

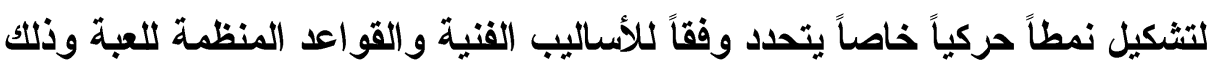

• أسـناذ المناهج وطرو التدريسر بكلية التربية الرياضية ووكيل الكلية اشئون البيئة وخدمة المجتمع جامعة بني سويف.

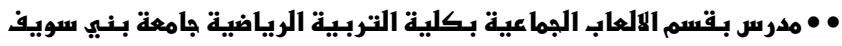

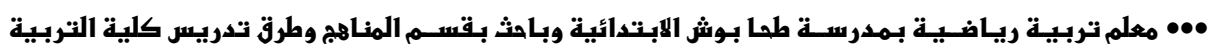


بغرض تحقيق نتائج محددة ويمكن القول أن المهارات الأســاسية في الكرة الطائرة تحتاج إلى وقت كبير لاكتســابها وإلى تدريب مســتمر مبنى على الأسـس العلمية

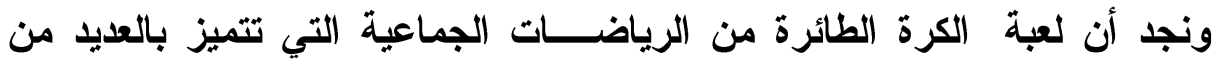
المهارات المتنوعة والتي تظورت وظهرت منذ نشأتها وحتى الآن.

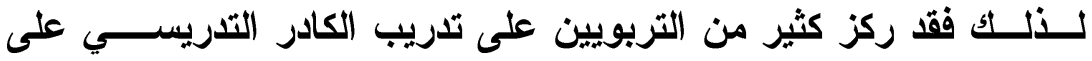

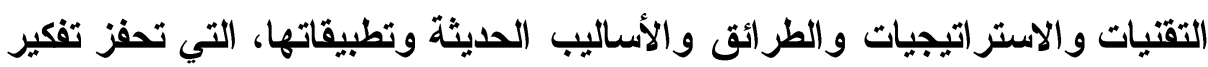

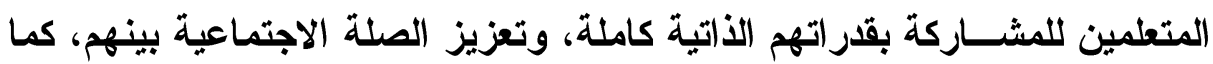
واســتخدمت هذه الاستر اتيجيات والطر ائق والأساليب التفكيرية في حل مشاكل في

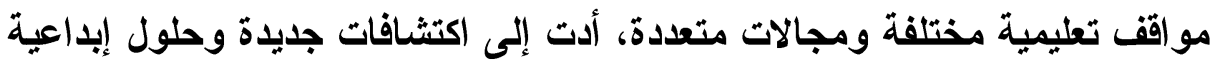

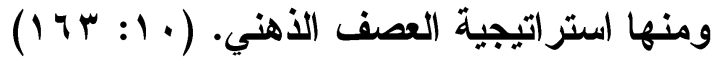

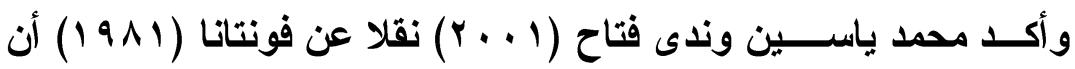
العصف الذهني هو طريقة للإتيان بالأفكار دون اعتبار لتقويمها، وهذا لا يعني ترك

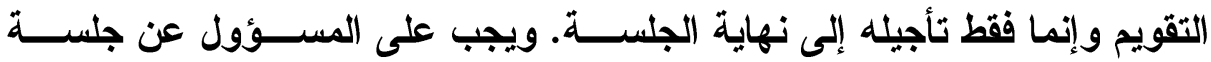

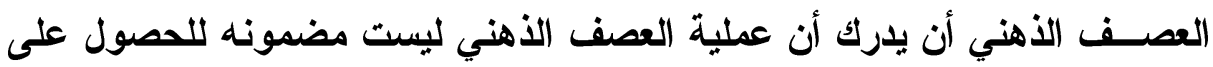
الأفكار الجديدة، فضــلا" عن ذلك فان اســتذدام العصف الذهني ليس مجرد وسيلة للتشجيع على طرح أفكار جديدة، ولكن كي يشجع المشاركين جميعهم على الإسهام

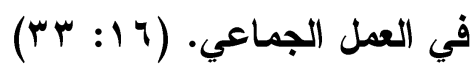

وفي هذا الصدد تذكر هناء محمد صالح (؟ . . ب) أنه على الرغم من تأكيد

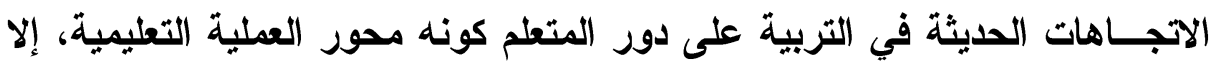

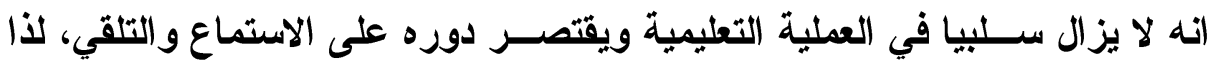
لابد من العمل على تهيئة الفرص أمام الطلبة لاكتسـاب الخبرات عن طريق التفكير

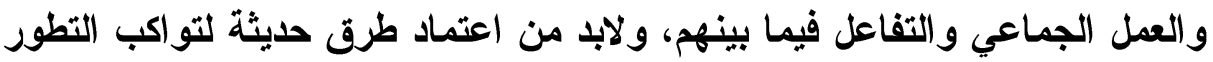

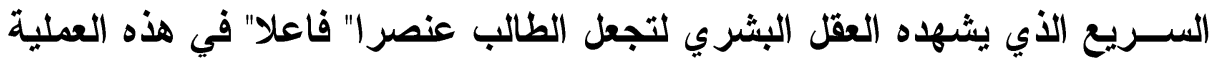

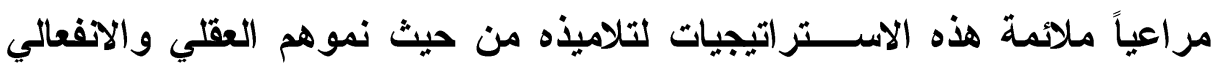

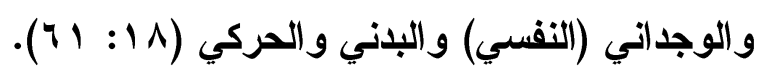

- ץ $\varepsilon$ - Website: http://www.bsu.edu.eg/Sector_Home.aspx?cat_id=13\# 
والمهارات الاساسية في الألعاب الرياضية الجماعية تعنى قدرة الفرد على

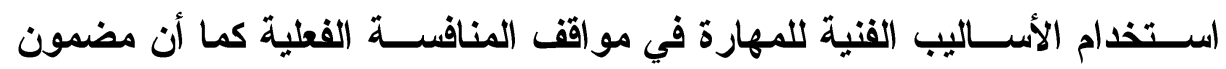

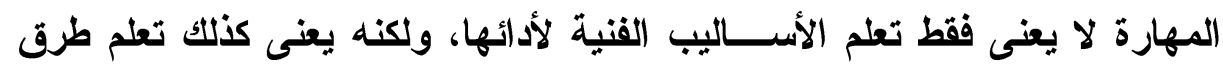

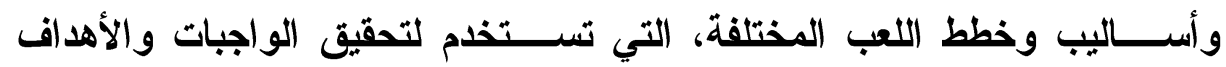
الجوهرية للتربية البدنية كالتحمل والســرعة والقوة والتي تخلم الأثــكال الكثيرة

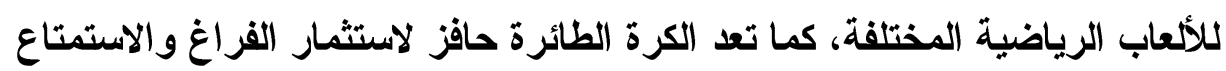

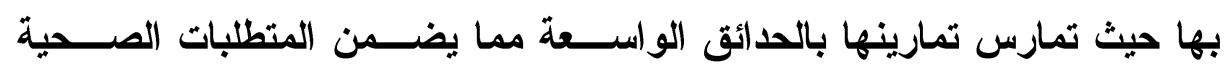

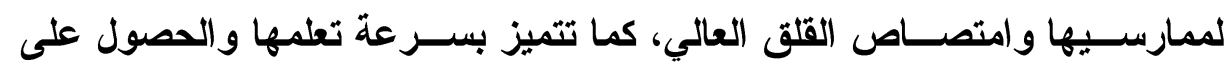

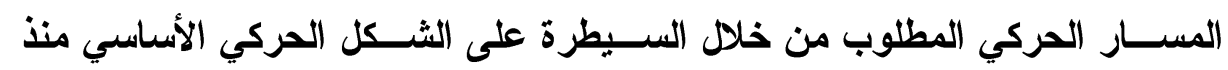

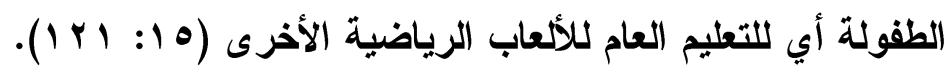
لذا بات من الضروري استخدام استراتيجيات حديثة في تنمية التفكير وهذه الاهري

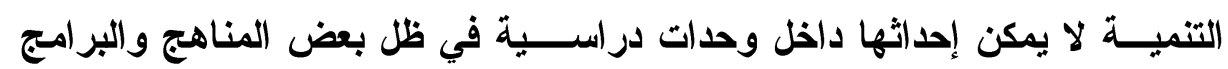

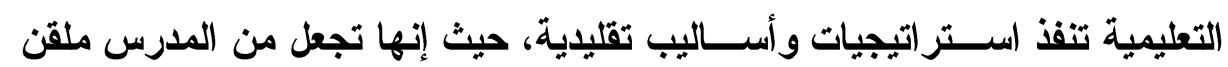

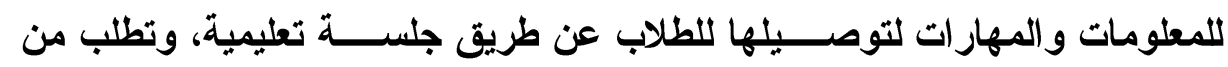
الطــالـب تذكر واســـترجاع تلكت المعلومات دون الاهتمام بتنمية القدرات العقلية ولاسيما التفكير.

واسـتنادا" لما ســق، فقد انصــب اهتمام الباحث في تحديد مثكلة بحثه كالتالي: - - ما هو أثر اســتخدام أسلوب العصف الذهني على تعلم المهارات الأساسية في الكرة الطائرة لاي تلاميذ المرحلة الابتدائية؟ هدف البحثث:

- يهدف البحث إل ة (وقفات ى: التعرف على تأثير اســتراتيجية العصــف

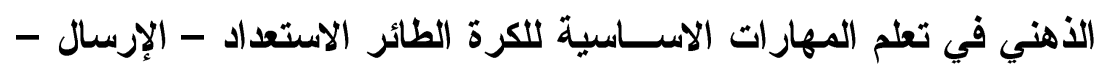

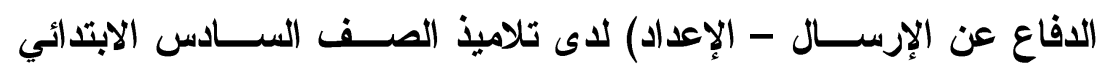

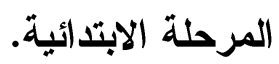

- $\bullet$ - Website: http://www.bsu.edu.eg/Sector_Home.aspx?cat_id=13\# E-mail: journal.science@uahoo.com 


\section{فروض البـهن:}

- توجد فروق ذات دلالة احصـائية بين القياسين القبلي والبعدي للمجموعة الضـابطة باســتخدام الأسلوب التقليدي في تعلم المهار ات الاساسية للكرة

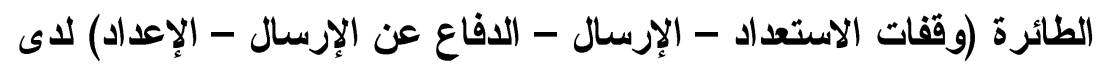

$$
\text { تلاميذ الصف السادس الابتدائي (قيد البحث). }
$$

- توجد فروق ذات دلالة احصـائية بين القياسين القبلي والبعدي للمجموعة البئ التجريبية باســتخدام أســلوب العصف الذهني في تعلم المهارات الاسـاسية

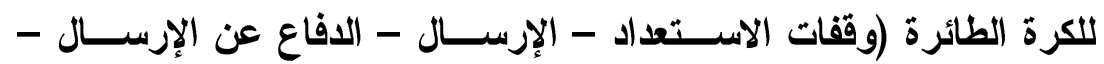
الإعداد) لاى تلاميذ الصف السادس الابتدائي المرحلة الابتدائية.

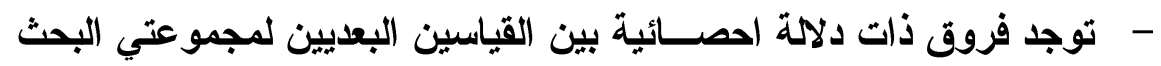
الضـابطة والتجريبية في تعلم المهارات الاســاسية للكرة الطائرة (وقفات

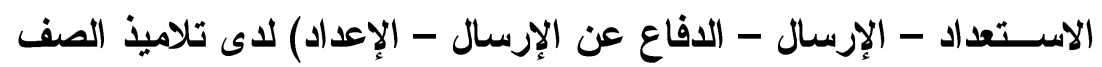
السادس الابتدائي المرحلة الابتدائية ولصالح المجموعة التجرئية الإسية. مصطلحات البهث:

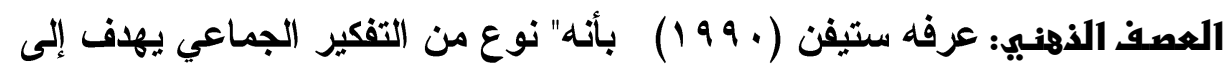

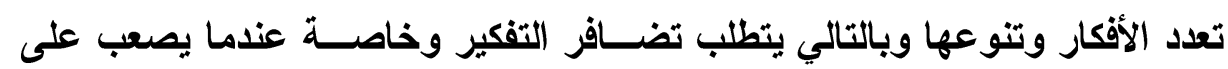

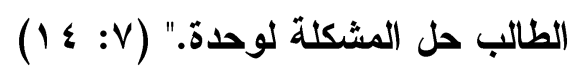

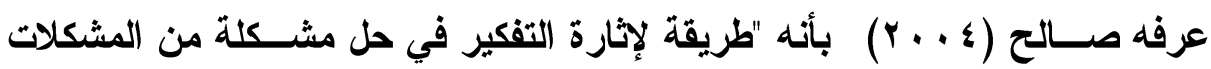

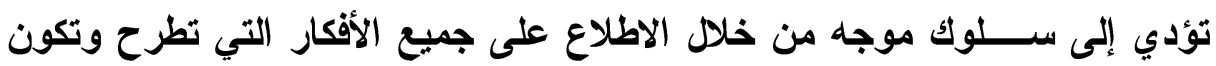

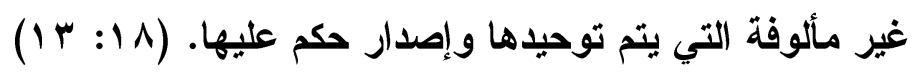
الدراسات السابقةة:

- دراسة عبد الستار الاليمي (ه . . r) بعنوان (أثر استخدام العصف الذهني في

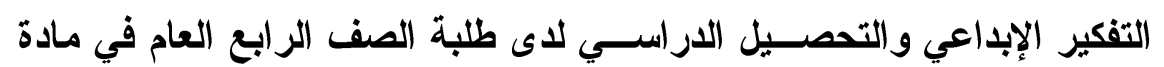

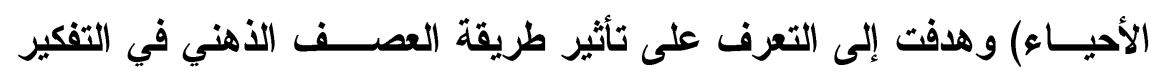

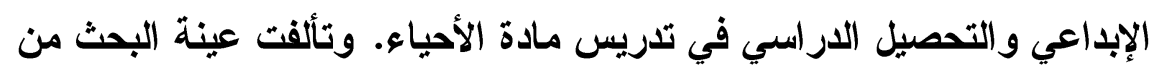


(ع •) طالبا "من طلبة المرحلة الرابع عام الذين يدرســـون في إحدى المدارس

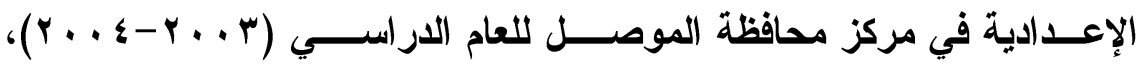

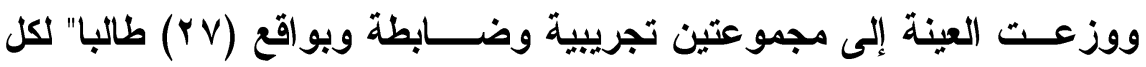

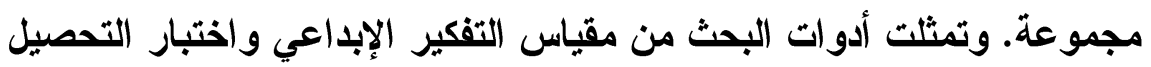

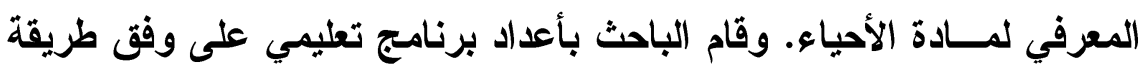

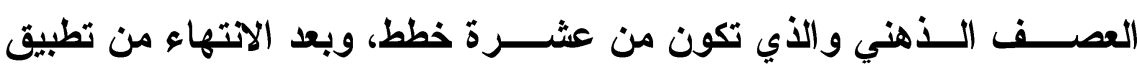

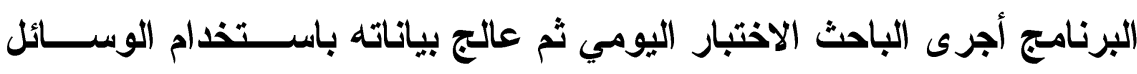
الإحصــائية. الوســط الحسابي والاتحر اف المعياري والاختبار الثاني للعينات

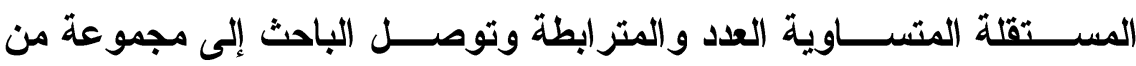
الاســتنتاجات أهمها وجود أثر لطريقة العصــف الذهني في تحســـين التفكير

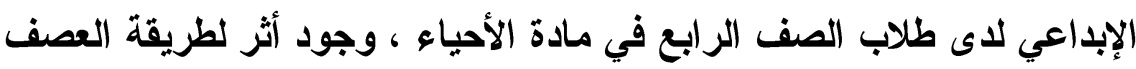

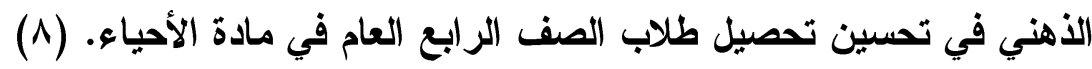

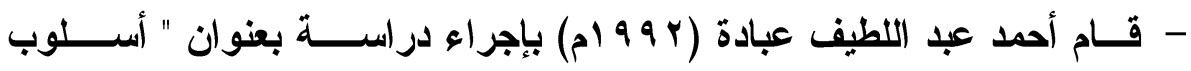

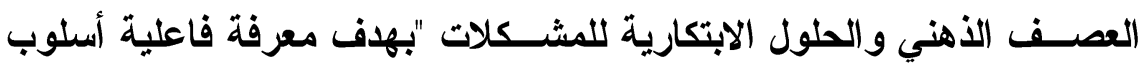

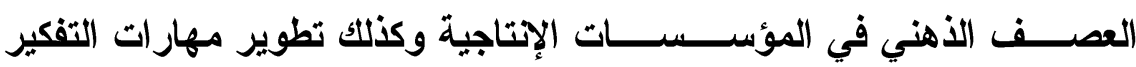

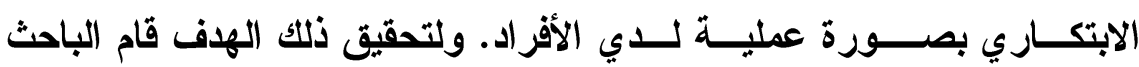
باســتخدام استراتيجيات وتكنيكات معينة أثبتت فعاليتها في مجال تنمية التفكير

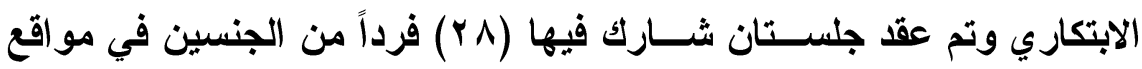
القيادة بمجالات التعليم والصــناعة و الاقتصــاد و الخدمات؛ مقسمين إلى ثلاث

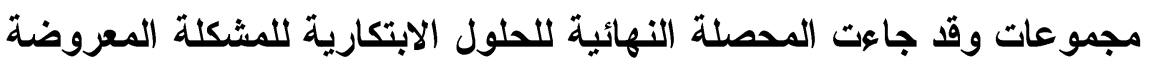

$$
\begin{aligned}
& \text { عشر حلول ابتكارية منتقاة. (r) } \\
& \text { إجراءات البحثْ: }
\end{aligned}
$$

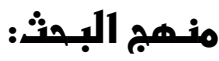

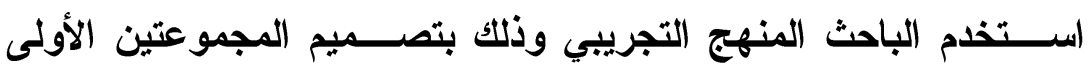
المجموعة الضابطة والثانية المجموعة التجريبية واستخدام القياس البعدي. 


\section{مجتمعر وعينة البحث: \\ مجتمهر البـن:}

اختار الباحث الصـف السادس الابتدائي بمدرسة طحا بوش الابتدائية بنين

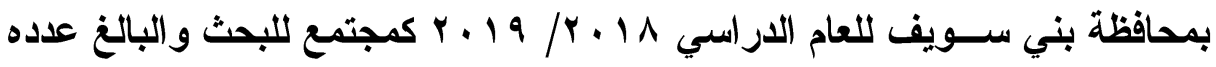
rه تلميذ فقط؛ وقد تم استبعاد المنقطعون ولاعبي الكرة الطائرة.

\section{عبنـة البهث:}

تم اختيار عينة البحث بالطريقة العمدية وقد اشـتملت العينة على عدد . ؛

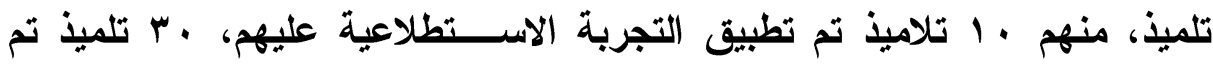

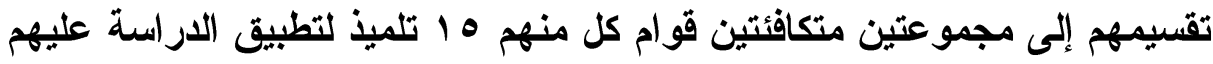

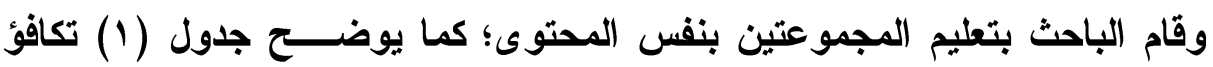

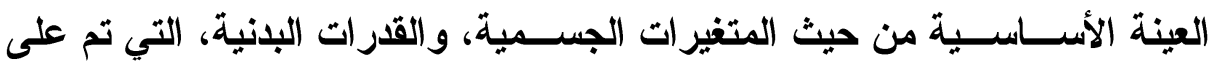
أساسها اجر اء عمليات التكافؤ.

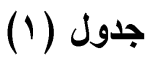

يوضح المتوسط الحسابي، و الوسيط، والاتحراف المعياري،

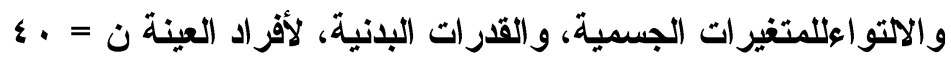

\begin{tabular}{|c|c|c|c|c|c|c|}
\hline الالتواء & الانحريار اف & الوسيط & المتوسطي & ولقياس & المتغير ات & r \\
\hline$\cdot, \leqslant 0$ & $V, \leqslant T_{0}$ & $1 \leq 0$ & $1 \leqslant 7, \leqslant 0$ & السم & الطول & 1 \\
\hline $1, r$ & $\cdot, \leqslant r q$ & Ir & IY,Yo & سنة & السن & $r$ \\
\hline$\cdot, r r q$ & $\Lambda, 7 \vee$ & $\varepsilon$. & $\varepsilon \cdot, 0 \vee 0$ & الكجم & الوزن & $r$ \\
\hline$\cdot, \cdot V r$ & $\cdot, 9 \cdot 1$ & $\Lambda, \leqslant \leqslant 0$ & $\wedge, \vee \backslash \wedge$ & الثانية & السرعة & $\varepsilon$ \\
\hline •, หรด & Y,|YI & $V$ & $7, \vee 0$ & السم & المرونة & 0 \\
\hline$\cdot, \varepsilon r q$ &., 01 & $\Lambda, \vee 0$ & $\Lambda, \vee \cdot \theta$ & الثانية & الرشاقة & 7 \\
\hline$\cdot, \varepsilon Y Y_{-}$ & $\cdot, \leqslant \wedge q$ & $V, \cdot Y O$ & 7,970 & الثانية & التو افق & 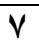 \\
\hline., $.9 r$ & $\cdot, Y 10$ & 1,490 & $1, \leqslant 0 Y$ & السم & قرة عضلات الرجلين & $\Lambda$ \\
\hline$\cdot, \cdot 9 \pi$ & $\cdot, Y \vee Y$ & $r, 19$ & Y,YI & السم & قرة عضلات الأراعين & 9 \\
\hline
\end{tabular}

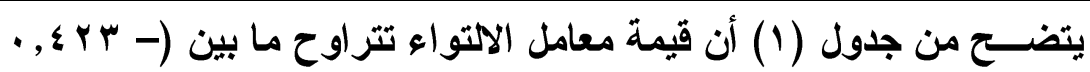

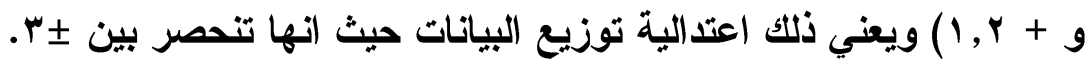

- $\Psi \Lambda$ - Website: http://www.bsu.edu.eg/Sector_Home.aspx?cat_id=13\# 


\section{جدول (r)}

المتوسط الحسابي و الانحر اف المعياري وقيم "ت" بين المجموعتين

التجريبية والضابطة في القياس القبلي للمتغيرات الجسمية، و القدرات البدنية لأفراد العينة $\mu \cdot=\dot{0}$

\begin{tabular}{|c|c|c|c|c|c|c|}
\hline \multirow{2}{*}{ ت } & \multicolumn{2}{|c|}{ المجموعة التجريبية } & \multicolumn{2}{|c|}{ المجموعة الضابطة } & \multirow{2}{*}{ المتغير ات } & \multirow{2}{*}{ م } \\
\hline & $\varepsilon$ & f & $\varepsilon$ & f & & \\
\hline$\cdot, \cdot, \leqslant 7$ & $\vee, \Lambda \cdot 1$ & $1 \leqslant V$ & $\Lambda, 1 \odot \Lambda$ & $1 \leqslant V, 1 M$ & الطول & 1 \\
\hline $1, Y \wedge \wedge$ & $\cdot, \varepsilon \wedge \wedge$ & Ir,rr & $\cdot, r \circ r$ & Ir,Irr & السن & $r$ \\
\hline$\cdot, \cdot \leq 1$ & $9,0 \leqslant 0$ & $\varepsilon \cdot, 7$ & $\Lambda, \varepsilon \mu$ & $\varepsilon \cdot, V M r$ & الوزن & $\mu$ \\
\hline., 10 & $\cdot, \wedge 10$ & $\wedge, \wedge 91$ & $1,11 \%$ & $\Lambda, 9 \leq 0$ & السرعة & $\varepsilon$ \\
\hline $1,0 r$ & $1, \wedge 9 \vee$ & $7, \wedge$ & I, qYY & 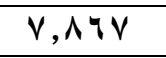 & المرونة & $\bullet$ \\
\hline$\cdot, Y 7 \varepsilon$ & $\cdot, V 10$ & $\Lambda, \Delta \mu V$ & $\cdot, \leqslant \wedge 1$ & $\Lambda, \leqslant \vee q$ & الرشاقة & 7 \\
\hline $1, \cdot r$ & $\cdot,\{Y 1$ & $V, \cdot Y Y$ & $\cdot, \leq \varepsilon$ & $\vee, 1 \wedge \varepsilon$ & التو افث & $\mathrm{V}$ \\
\hline $1,0 Y 7$ &., 107 & $1, \leqslant 07$ & $\cdot, r \cdot \Lambda$ & $1, r \Delta r$ & قرة عضلات الرجلين & $\Lambda$ \\
\hline 1,019 & $\cdot, Y \wedge \uparrow$ & $r, Y \wedge 1$ & $\cdot, Y \vee r$ & Y,IYT & قرة عضلات الذراعين & 9 \\
\hline
\end{tabular}

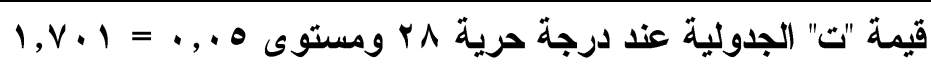

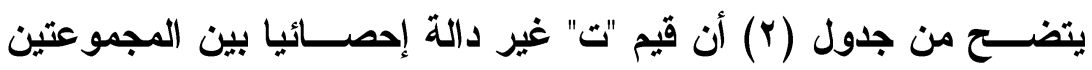

الضـــابطة والتجريبية في المتغيرات البذنية ويعنى ذلك أن المجموعتين متكافيتتين

قبل بدأ التجربة.

\section{جدول (r)}

المتوسط الحسابي و الآحر اف المعياري وقيم "ت" بين

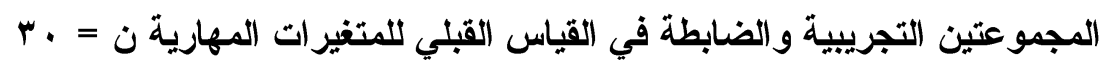

\begin{tabular}{|c|c|c|c|c|c|c|}
\hline \multirow{2}{*}{ ت } & \multicolumn{2}{|c|}{ المجموعة التجريبية } & \multicolumn{2}{|c|}{ المجموعة الضابطة } & \multirow{2}{*}{ المتغيرات } & \multirow{2}{*}{ p } \\
\hline & $\varepsilon$ & p & $\varepsilon$ & 5 & & \\
\hline$\cdot, Y Y \leqslant$ & - & I, АтV & $\cdot, \vee \vee 99$ & 1,9rr & وقفة الاستعداد & 1 \\
\hline$\cdot, 0 Y 0$ & $\cdot, 7 \leqslant$ & 1,OH & $\cdot, V Y \leqslant$ & $1,77 V$ & التحركات & $r$ \\
\hline$\cdot, 114$ &., 971 & Y,qur & 1 & $r$ & التمرير من أعلى & $\mu$ \\
\hline., 190 & $\cdot, 910$ & r,Irr & $\cdot, 971$ & $r, .7 V$ & التمرير من أسفل & $\varepsilon$ \\
\hline - YTSO & $\cdot, \mathrm{V} 04$ & $r$ & $\cdot, \mathrm{\vee} 99$ & T,.TV & الإعداد & 0 \\
\hline., 194 & $\cdot, 9 \wedge 4$ & $r, \varepsilon$ &., 910 & $r, \leqslant T V$ & الارسـال من أعلى & 7 \\
\hline$\cdot, I V T$ & $1,1 Y 1$ & $r, \tau$ & $\cdot, 99$ & $r, O H r$ & الارسال من أسفل & $\mathrm{V}$ \\
\hline
\end{tabular}

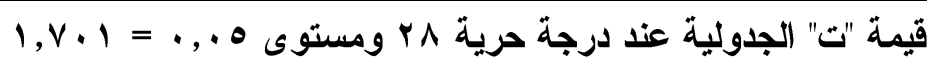

Beni-Suef Journal Of Physical Education And Sport Sciences (B.J.P.E.S.S)

- $\uparrow q$ - Website: http://www.bsu.edu.eg/Sector_Home.aspx?cat_id=13\#

E-mail: journal.science@uahoo.com 
يتضـــح من الجدول (r) أن قيم "ت" غير دالة إحصــائيا بين المجموعتين الضــابطة و التجريبية في المتغيرات المهارية ويعنى ذلك أن المجموعتين متكافئتين قبل بدأ التجربة. استخدم الباحث الأدوات والاذتبارات النالية لجمع البيانات وهي:

$$
\begin{aligned}
& \text { أدوات جمع البهانات: } \\
& \text { أولاً - الأجهزة و الأدوات } \\
& \text { ثانياً - الاختبار ات: الاجغز والأو } \\
& \text { 1- الاختبارات البلنية. } \\
& \text { r - الاختبار ات المهارية. } \\
& \text { أولًا - الأجهمزة والأدوات: }
\end{aligned}
$$

جهاز رســتاميتر لقياس الطول بالســـم والوزن بالكجم. - ســـاعة إيقاف

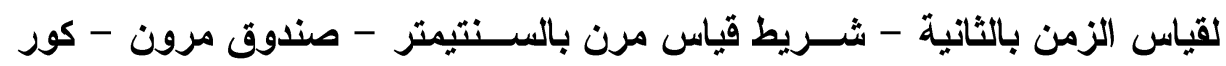

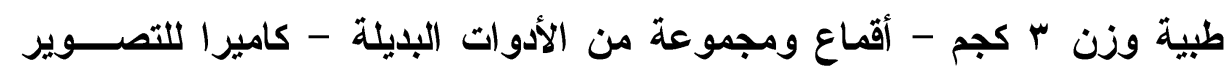

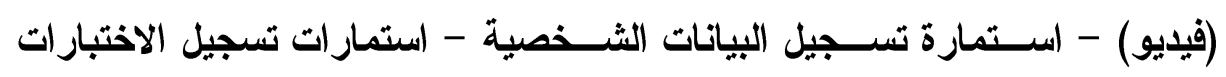
البلنية - استمارة تقييم مستوى الأداء المهارى إعداد الباحث . ثانباً: الافتباراتة: الافتبارات البدنبة:

قام الباحث بإجراء مقابلات شــــــية مع ( • 1) عشرة خبراء في مجال

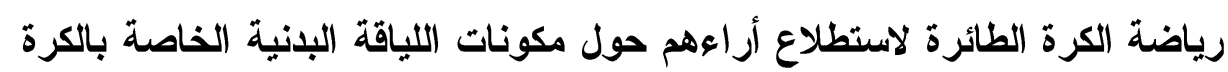

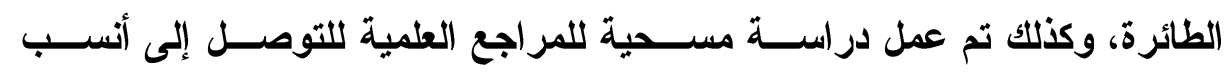

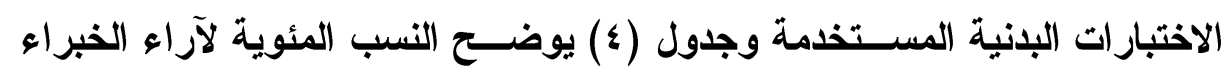

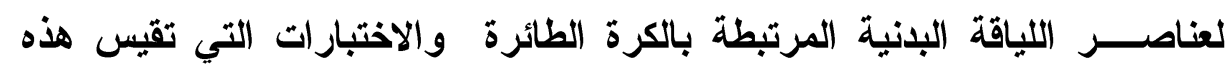
العناصر: 
جدول (ع)

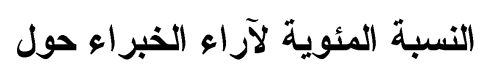

عناصر اللياقة البدنية المرتبطة بالمهارة قيد البحث والاختبار ات التي تقيس هذه العناصر ألقرل

\begin{tabular}{|c|c|c|c|}
\hline الاختبار & المئويبة & العنصر & p \\
\hline العدو (·•م) & $\% \wedge$. & السرعة & 1 \\
\hline ثنى الجذع أماماً من الوقوف & $\% \wedge$. & المرونة & r \\
\hline 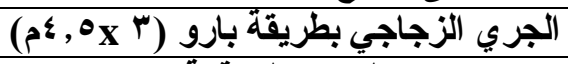 & $\% \wedge$. & الرشـاقة & $r$ \\
\hline الاوائر المرقمة & $\% \wedge$. & التو افقق & $\varepsilon$ \\
\hline الوثُب العريض من الثبات & $\%$ & قرةة عضلات الرجلين & 0 \\
\hline دفع كرة طبية زنة (广ّ) كجم & $\% \wedge$. & قدرة عضلات الأر اعين & 7 \\
\hline
\end{tabular}

\section{صدو وثبات الافتبارات البدنـية:}

\section{أ-1الصدق : صدق التكوين الفرضي (الفُروق بينز الجما عات):}

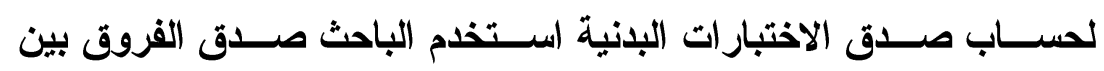

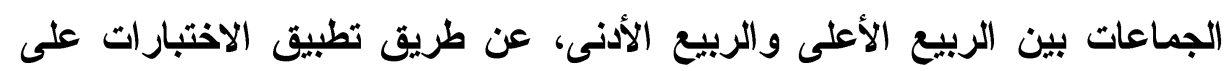

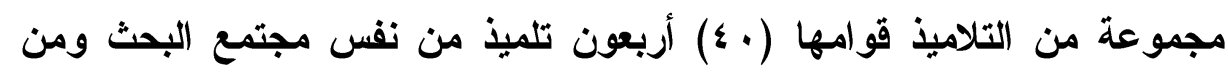

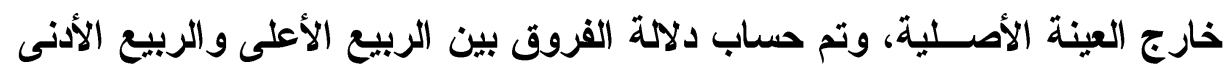
وجدول (0) يوضح ذلتك.

جدول (0)

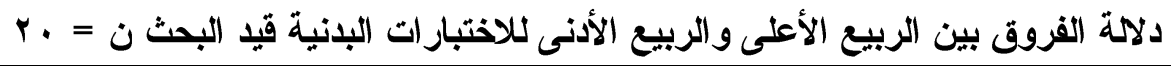

\begin{tabular}{|c|c|c|c|c|c|c|c|}
\hline \multirow{2}{*}{ اتجاه } & \multirow{2}{*}{ 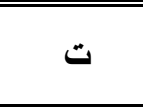 } & \multicolumn{2}{|c|}{ الربيع الأعلى } & \multicolumn{2}{|c|}{ الربيع الأدنى } & \multirow{2}{*}{ المتغير } & \multirow{2}{*}{ r } \\
\hline & & $\varepsilon$ & s & $\varepsilon$ & r & & \\
\hline \multirow{6}{*}{$\frac{\overline{3}}{3}$} & $11, V Y \leq$ &.,$\pi \mid r$ & $9,9 \leq 9$ &.,$\Delta r^{\prime}$ & $V, 79 v$ & السرعة & 1 \\
\hline & $19, V Y Y$ & $\cdot, \varepsilon Y Y$ & $9, Y$ & $\cdot, \mathrm{V} \sim \wedge$ & $r, q$ & المرونة & $\bar{r}$ \\
\hline & $1 \vee, r \wedge q$ & - , YYT & $q, \varepsilon \cdot 1$ & $\cdot, \cdot \times 1$ & $\Lambda, 1 Y$ & الرشاقة & $r$ \\
\hline & $1 T, V \leq V$ & $\cdot, r \cdot q$ & $V, 0, Y$ &., $19 \mathrm{~V}$ & Y,YOY & التو (فق & $\varepsilon$ \\
\hline & $1 \leq, 790$ & $\cdot, ., 14$ & $1, V Y \leq$ & $\cdot, \cdot \wedge \wedge$ & 1,190 & قرة عضلات الرجلين & 0 \\
\hline & IV,Trq & $\cdot, .199$ & Y,OVI & $\cdot, .94$ & $1, \wedge \bullet \wedge$ & قدرة عضلات الذراعين & 7 \\
\hline
\end{tabular}

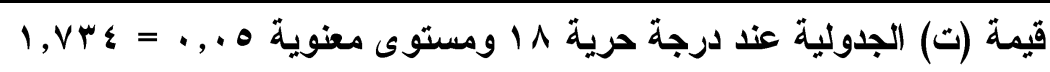

- \& - Website: http://www.bsu.edu.eg/Sector_Home.aspx?cat_id=13\#

E-mail: journal.science@uahoo.com 


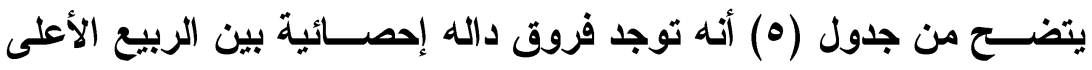

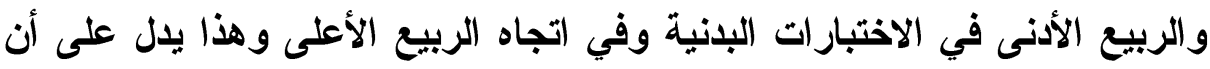

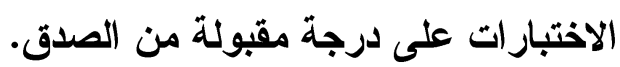

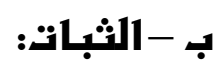

تم حسـاب ثبات الاختبارات قيد البحث عن طريق التطبيق الأول والتطبيق

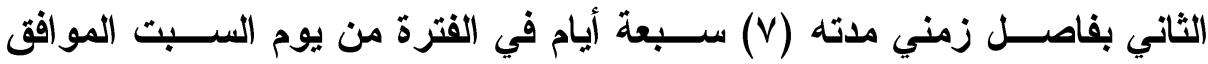

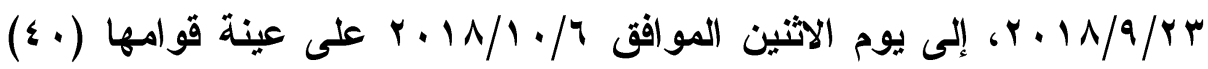

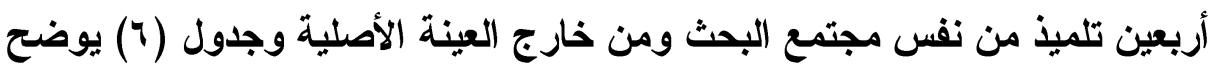
معامل الارتباط بين التطبيق وإعادة التطبيق. جدول (7) ع (7)

معاملات الارتباط بين التطبيق وإعادة التطبيق للاختبارات البذنية قيد البحث ن = . ـ

\begin{tabular}{|c|c|c|c|c|c|c|}
\hline \multirow{2}{*}{ J } & \multicolumn{2}{|c|}{ إعادة التطبيق } & \multicolumn{2}{|c|}{ التطبيق } & \multirow{2}{*}{ المتغير } & \multirow{2}{*}{ p } \\
\hline & $\varepsilon$ & 5 & $\varepsilon$ & م & & \\
\hline - ,999 & $\cdot, 9 \cdot 4$ & $\Lambda, \vee \curlyvee \diamond$ & $\cdot, 9 \cdot 1$ & $\wedge, \vee \backslash \wedge$ & السرعة & 1 \\
\hline •, १人ץ & $r, . r Y$ & $\checkmark, \vee \vee 0$ & $r, l$ & T,VYO & المرونـة & $r$ \\
\hline$\cdot, 991$ &., 0.0 & $\Lambda, \vee \cdot \varepsilon$ & $\cdot, 01$ & $\Lambda, \vee, \bullet$ & الرشاقة & $r$ \\
\hline$\cdot, 9 \wedge \vee$ & $\cdot, 0,4$ & $7,9 \wedge 9$ & $\cdot, \leqslant \wedge 9$ & 7,970 & التو افقت & $\varepsilon$ \\
\hline., 901 & $\cdot, Y \backslash \leqslant$ & $1, \leqslant V$ & $\cdot, Y 10$ & $1, \leqslant 0 Y$ & قدرة عضلات الرجلين & 0 \\
\hline$\cdot, \wedge 9\{$ & •, & Y,YYOO & $\cdot$, Y VY & $r, r_{1}$ & قدرة عضلات الذراعين & 7 \\
\hline
\end{tabular}

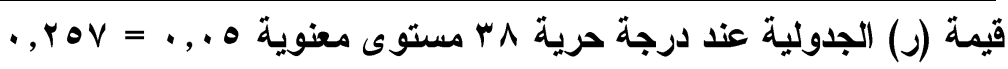

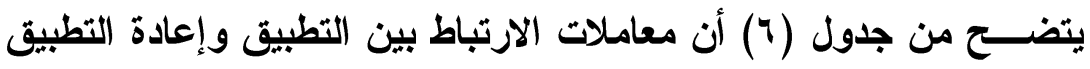

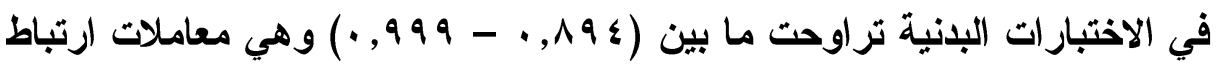

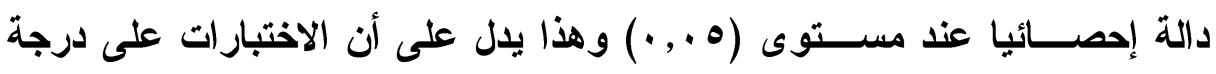
مقبولة من الثبات.

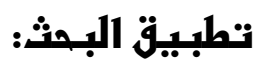
قام الباحث بتطبيق البحث على عينة البحث كالآتي: 


\section{التجربة الاستطلا عية:}

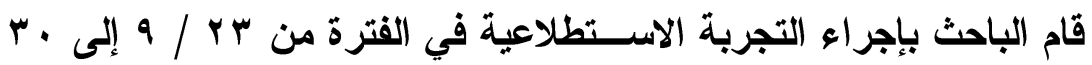

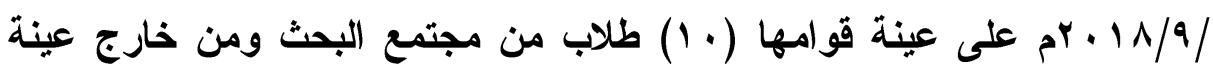
البحث وذلكك للتأكد سلامة التطبيق و البرنامج و التأكد من أدوات البحثي البحت

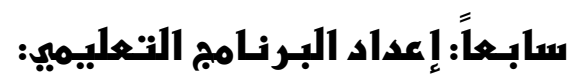

تم إعداد البرنامج التعليمي بإتباع الخطوات التالية:

ا. قام الباحث بمســـح مرجعي للكتب العربية والأجنبية في حدود وقدرة الفيلية

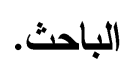

r. r. إجراء مسح للاراسات والبحوث المتعلقة وذات الصلة بمتغيرات الدراسة. r. المقابلة الثــصية مع الخبراء في مجال رياضة الكرة الطائرة و المناهج

$$
\text { 1) أهداف البرنامج: التدريس. }
$$

يهذف البرنامج إلى تعليم الطلاب المهارات الأســــــــية للكرة الطائرة

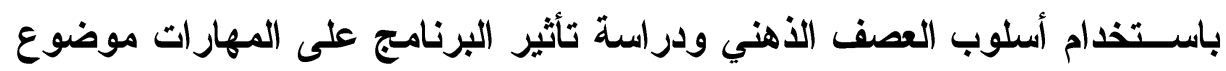

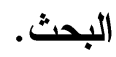

\section{|r) بعض الشروطوالمعايير البرنـامج التعليمير:

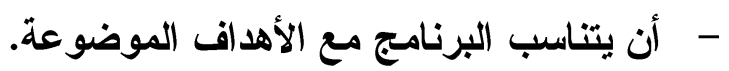

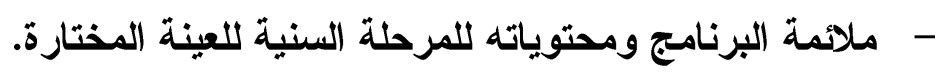
- - مرونة البرنامج وقابليته للتعديل.

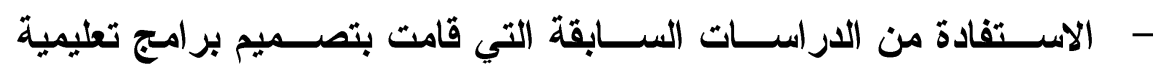
مشابهة.

- - الاستمر ارية والانتظام في ممارسة البرنامج حتى يعود بالفائدة المرجوة. - - مراعاة الفروق الفردية عند وضع البرنامج.

- $\&$ - Website: http://www.bsu.edu.eg/Sector_Home.aspx?cat_id=13\# E-mail: journal.science@uahoo.com 
التجربة الأساسية:

القياسات القبلية:

تم إجراء القياســات القبلية لأفراد عينة الدراســة في الفترة من الأحد

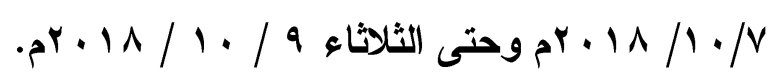

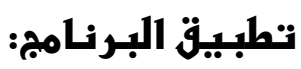

تم إجراء التجربة الأساسية على أفراد العينة الأساسية في الفترة من الأحد

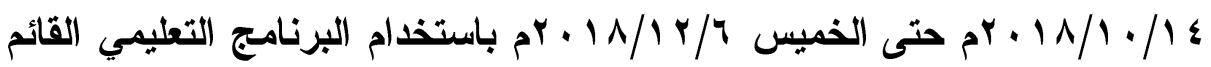

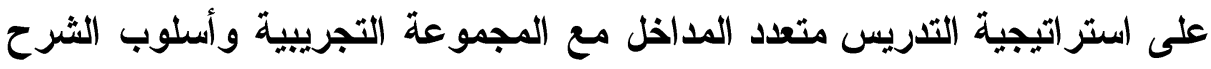
و العرض مع المجموعة الضابطة وتم ذلك في إطار تقسيم عدد الوحدات الأسبوعية لتشتمل على وحدة واحدة أسبوعياً. 1القياسات البعدية:

تم إجراء القياســات البعدية لأفراد عينة البحث وبنفس شــروط وأدوات

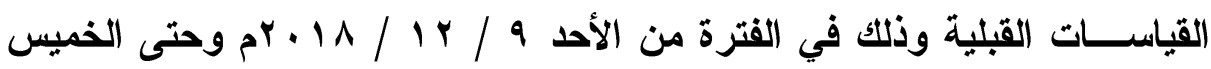

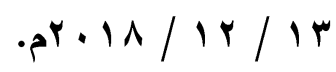

\section{المعالجة الإصطائية:}

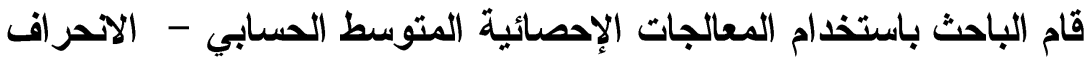

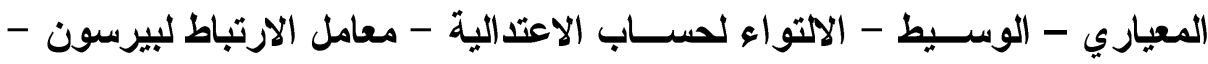

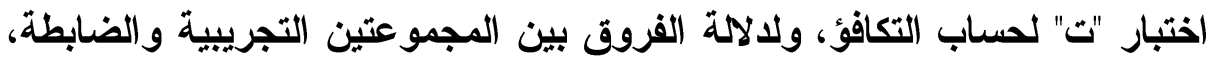
ولــلـالــة الفروق بين القياس القبلي والبعدي لكل من المجموعتين التجريبية و والضابطة .

وقد تم الاستعانة ببرامج الحزم الإحصائية (SPSS)، وقد ارتضى الباحث

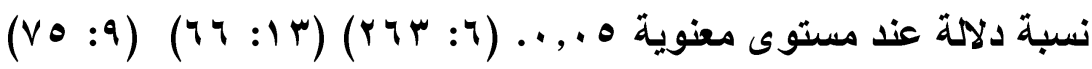

- $\varepsilon \varepsilon$ - Website: http://www.bsu.edu.eg/Sector_Home.aspx?cat_id=13\# E-mail: journal.science@uahoo.com 


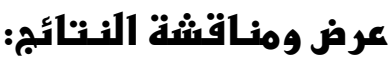

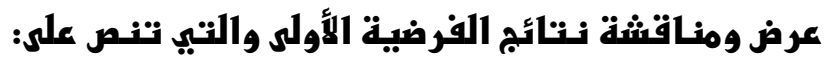

- توجد فروق ذات دلالة احصـائية بين القياسين القبلي و البعدي للمجموعة

الضـابطة باســتخدام الأسلوب المعتاد في تعلم المهارات الاساسية للكرة

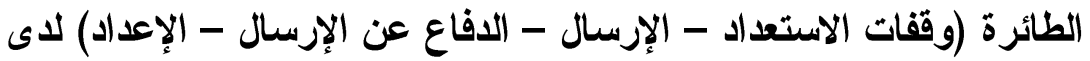

تلاميذ الصف السادس الابتدائي (قيد البحث).

جدول (v)

دلالة الفروق بين القياسين القبلي

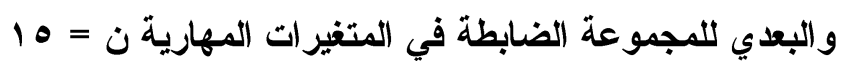

\begin{tabular}{|c|c|c|c|c|c|c|}
\hline 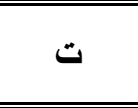 & المعياري & الفرق & البعدي & القبلي & المتغير & م \\
\hline $1 \varepsilon, 0 \mathrm{VI}$ & $1,1 \wedge \mathrm{V}$ & $\{, \xi T V$ & $7, \varepsilon$ & $1,94 \pi$ & وقفة الاستعداد & \\
\hline $14,9.4$ & $1, r 04$ & $\varepsilon, \Lambda T V$ & 7,OKY & $1,74 \mathrm{~V}$ & التحركات & $r$ \\
\hline ד דז & $r, T O \Lambda$ & $r \&, q \Gamma r$ & YV,qTr & $r$ & التمرير من أعلى & $r$ \\
\hline$r r, v \leqslant q$ & Y,YOT & Y.,OYT & $r T, T$ & $\Gamma, . T V$ & التمرير من أسفل & $\varepsilon$ \\
\hline Q,VYV & $1, \varepsilon \wedge \uparrow$ & r,V VTr & $0, \Lambda$ & $Y, . T V$ & الإعداد & 。 \\
\hline $19, r Y Y$ & $1, V Y \varepsilon$ & $\Lambda, \uparrow$ & Ir,. TV & $r, \Sigma \Psi V$ & الارسال من أعلى & 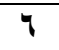 \\
\hline$r q, 9, \varepsilon$ & $1,0 . Y$ & 11,7 & $10,1 \% \pi$ & r,orr & الارسال من أسفل & \\
\hline
\end{tabular}

يتضــح من جدول (V) وجود فروق دالة إحصــائية بين القياسـين القبلي

و البعدي للمجموعة الضابطة في اتجاه القياس البعدي في مستوى الأداء المهارى.

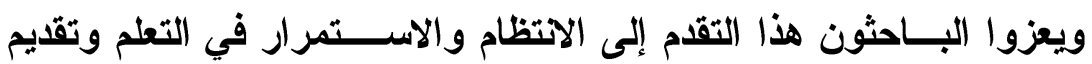

بعض المعلومات عن النواحي الفتية وطريقة الأداء للمهارات كما يعزوا الباحثئون

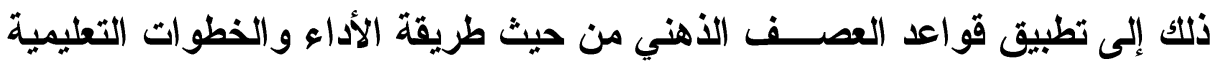

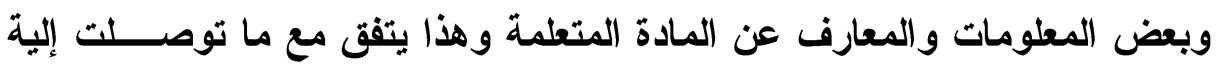

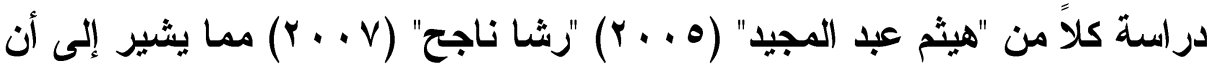

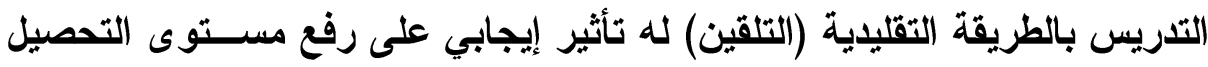

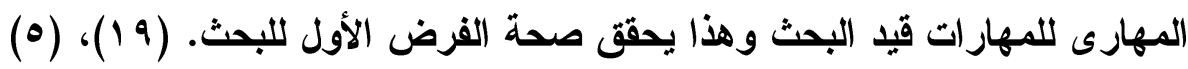

- $\&$ ○ - Website: http://www.bsu.edu.eg/Sector_Home.aspx?cat_id=13\# E-mail: journal.science@uahoo.com 


\section{عرض ومناقشة نـنائج الفرضية الثانية والني تنص على:}

- توجد فروق ذات دلالة احصـائية بين القياسين القبلي والبعدي للمجموعة والنئ

التجريبية باستخدام استراتيجية التدريس متعدد المداخل في تعلم المهارات الاساسية للكرة الطائرة (وقفات الاستعداد - الإرسال - الدفاع عن الإرسال

- الإعداد) لاى تلاميذ الصف السادس الابتدائي المرحلة الابتدائية.

$$
\text { جدول (^) }
$$

دلالة الفروق بين القياسين القبلي

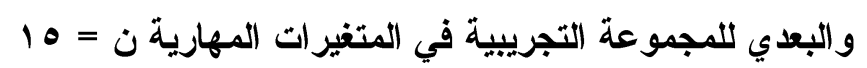

\begin{tabular}{|c|c|c|c|c|c|c|}
\hline ت & الالاحيرافي & الفرق & البعدي & القبلي & المتغير & م \\
\hline
\end{tabular}

\begin{tabular}{|c|c|c|c|c|c|c|}
\hline$r \cdot, r \Lambda \varepsilon$ & $\cdot, \vee \vee 99$ & Y,YTV & $\Lambda, 1 \mu r$ & I, ATV & وقفة الاستعداد & 1 \\
\hline IN,OHV & 1, ros & 7 & V,OHY & 1,Orr & التحركات & $r$ \\
\hline$r 9,79 r$ & $r, \wedge \vee \Delta$ & Yq, \& TV & rY, s & Y,qur & التمرير من أعلى & $\mu$ \\
\hline$r \wedge, \leqslant 01$ & r,ro & rT,RTr & Y४,\& ४ & r,Irr & التمرير من أسفل & $\varepsilon$ \\
\hline $1 \varepsilon, O Y \wedge$ & $1, \leqslant 0 V$ & $0, \& 7 V$ & $V, \varepsilon 7 V$ & $r$ & الإعداد & 0 \\
\hline $\mid V, 791$ & $Y, 00 \leqslant$ & $11,79 V$ & $10, .7 \mathrm{~V}$ & $r, \varepsilon$ & الارسال من أعلى & 7 \\
\hline$r Y, V \leqslant V$ & I,T & IT,VRr & IV,rTH & $r, \uparrow$ & الارسال من أسفل & V \\
\hline
\end{tabular}

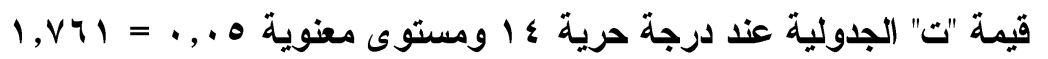

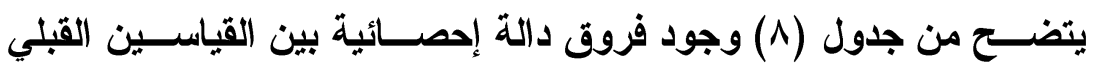

و البعدي للمجموعة التجريبية في اتجاه القياس البعدي في مستوى الأداء المهارى.

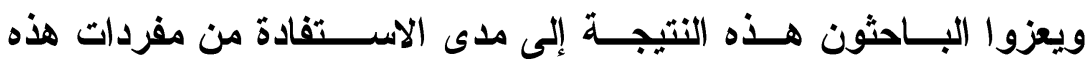

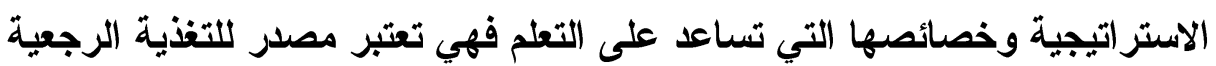
لاى المبتدئين، وهذا ما يساعد على اكتساب المعلومات والمعارف المرتبطة بالمادة

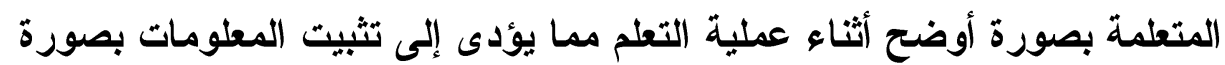

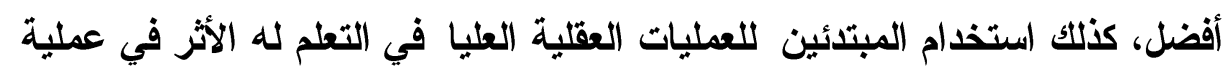

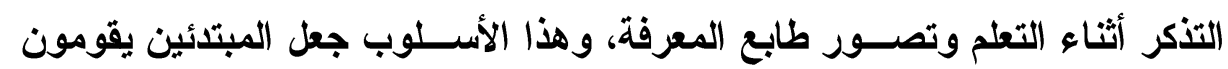

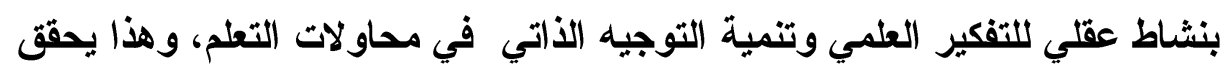
صحة الفرض الثاني للبحث.

- $\$ - Website: http://www.bsu.edu.eg/Sector_Home.aspx?cat_id=13\# E-mail: journal.science@uahoo.com 


\section{عرض ومناقشة نـنائج الفرضية الثالثة والتي تنـم على:}

- توجد فروق ذات دلالة احصـائية بين القياسين البعديين لمجموعتي البحث

الضـابطة والتجريبية في تعلم المهارات الاســــــية (وقفات الاستعداد -

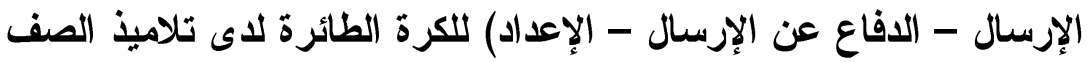

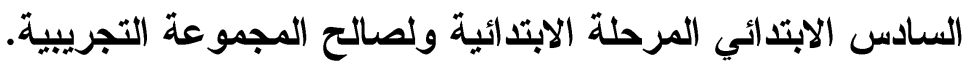

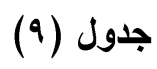

دلالة الفروق بين القياسين البعديين

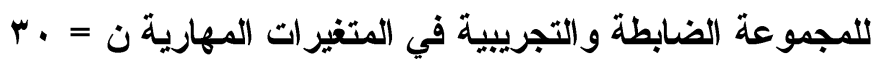

\begin{tabular}{|c|c|c|c|c|c|c|}
\hline \multirow{2}{*}{ ت } & \multicolumn{2}{|c|}{ التجريبية } & \multicolumn{2}{|c|}{ الضابطة } & \multirow{2}{*}{ المتغير } & \multirow{2}{*}{ م } \\
\hline & $\varepsilon$ & r & $\varepsilon$ & p & & \\
\hline $0, \leqslant \Psi \Lambda$ & $\cdot, \wedge \Psi \varepsilon$ & $\Lambda, 1 \mu \mu$ & $\cdot, 91$ & $7, \xi$ & وقفة الاستعداد & 1 \\
\hline$r, \wedge \vee r$ & $\cdot, \Lambda \Gamma \xi$ & V,OHr & 1,97 & $9, O H Y$ & التحركات & r \\
\hline$\varepsilon, Y \wedge r$ & $r, \cdot \leq r$ & $r, \xi$ & $Y, 701$ & $r V, q r r$ & التمرير من أعلى & $r$ \\
\hline$r, r V V$ & r, r. . & $Y \Psi, \leqslant T V$ & $Y, \leqslant \leqslant \leqslant$ & Yr,T & التمرير من أسفل & $\varepsilon$ \\
\hline דוזד, & $1,1 \mathrm{YO}^{\circ}$ & $V, \Sigma T V$ & $1, r V r$ & $0, \Lambda$ & الإعداد & 0 \\
\hline$\varepsilon, 991$ & $1, \wedge \vee$. & $10, .7 V$ & I, rAv & IY,.TV & الارسال من أعلى & 7 \\
\hline$\varepsilon, . \wedge$. & $1, v \circ q$ & IV,rrr & $1,1,0$ & $10,1 \mathrm{rr}$ & الارسال من أسفل & $\mathrm{v}$ \\
\hline
\end{tabular}

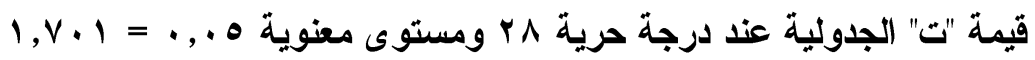

يتضـــح من جدول (9) وجود فروق دالة إحصــائية بين القياسين البعديين

للمجموعتين الضابطة والتجريبية في اتجاه القياس البعدي للمجموعة الضابطة في

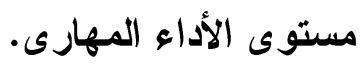

يتضــح من الجدول (9) بان قيم (ت) المحســوبة أكبر من الجدولية وهذا

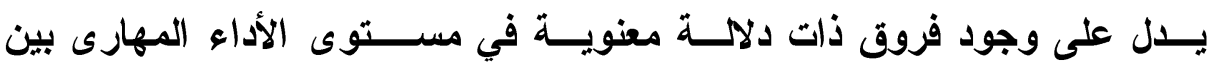

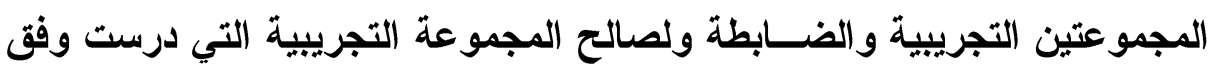

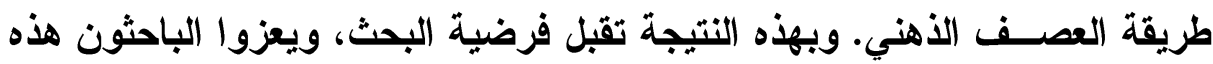

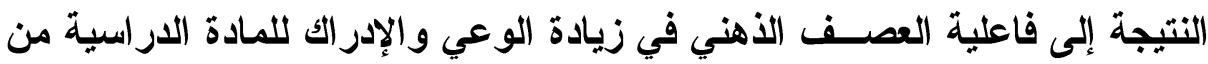
قبل الطلاب وذلك بسـبب أن هذه الطريقة قد وفرت قاعدة عريضة من المعلومات

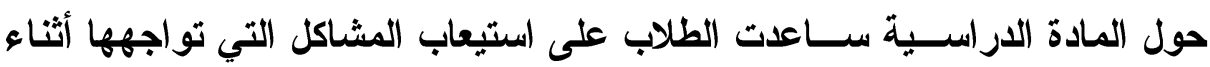

- \&V - Website: http://www.bsu.edu.eg/Sector_Home.aspx?cat_id=13\# 
المـــــــــة وتطوير القوة الإدراكيــة لــــى المتعلمين، فتزيد من طلاقة أفكارهم وتنوعها و أصالتها، وبهذه الطريقة تجعل الطالب في موقف نشط وفعال.

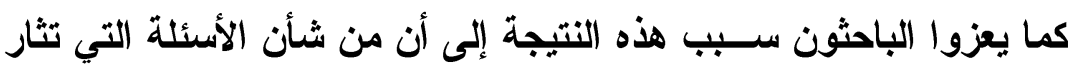

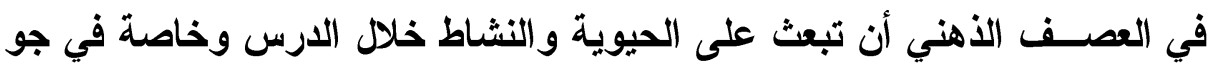
جماعي يســوده الألفة والتعاون التي تدفع الطلاب إلى التفكير وإجراء المناقشـــات بين الطلاب أنفسهم من جهة وبين المدرس والطلاب من جهة أخرى. ويؤكد القلا أن هذه الطريقة تفيد في التطور الحضـــــاري لطر ائق تفكيرنا

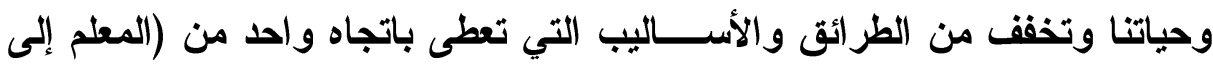

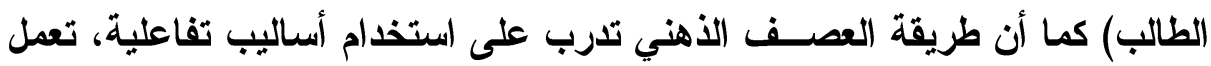

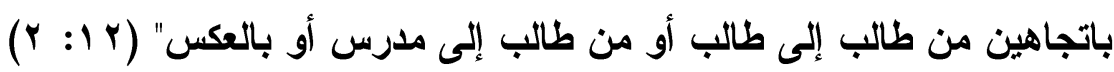

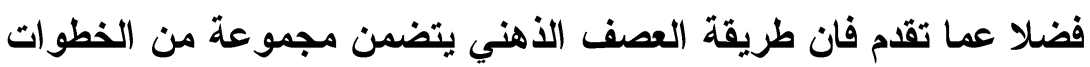

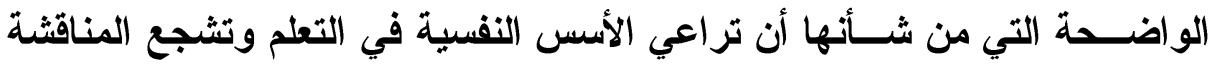
الجماعية وتر اعي الفروق الفردية بين الطلاب.

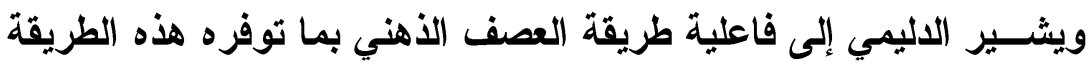
من إطلاق عنان التفكير والإتيان بما هو غير مألوف من الأفكار كما أن تحقيق مبدأ

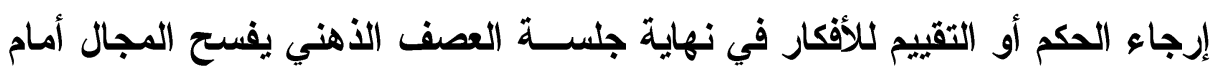

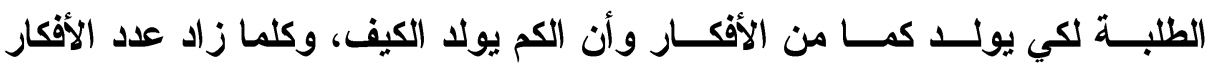

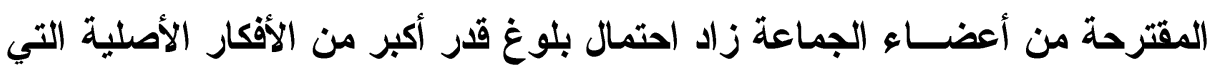

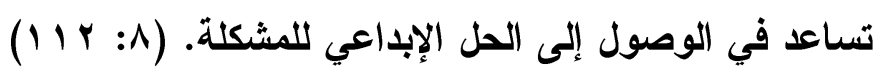
كما تعمل اســتر اتيجية العصــف الذهني على إكســــاب المتعلم و المتعلمة مهــار ات ســلوكية مثل التنظيم والثــــرح وقبول وجهات نظر الآخرين من خلال المساعدة الجماعية في توليد الأفكار، وهي تعمل على تضيق الفجوة بين المعلومات

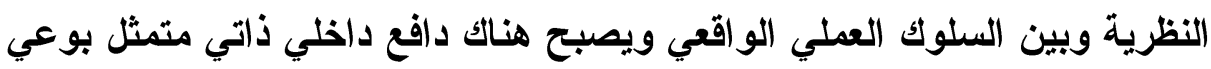

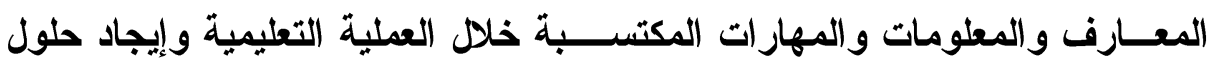
للمثكلات بما يتلاعم وواقع البيئة التعليمية. واتفقت هذه النتيجة مع دراسة ولئه صالح 


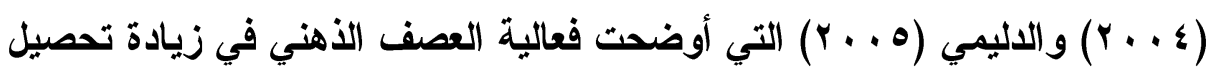

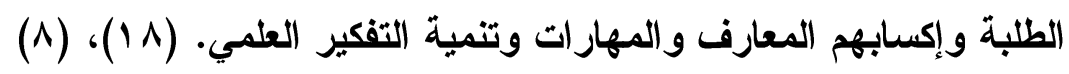
الاستنتناجات والتوصيات:

|اساستنتاجات:

- فاعلية استخدام استراتيجيتي العصف الذهني والمحاضرة في رفع مستوي

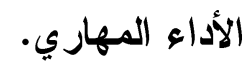

- تفوق افراد المجموعة التجريبية التي درســت وفق اسـتراتيجية العصف

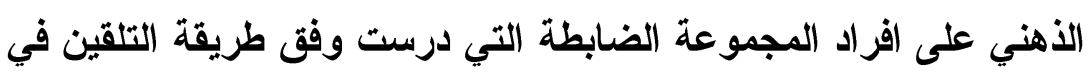

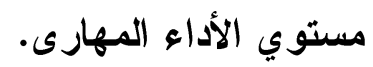

- - إن تأثير اسـتراتيجية العصف الأهني كانت الأفضل من استراتيجية التلقين في تنمية التفكير العلمي لاي عينة الدراسة. التـوصيات:

- التأكيد على اســتخام طريقة العصــف الذهني بوصـفه أفضل من طريقة التلقين في رفع المستوي المهارى.

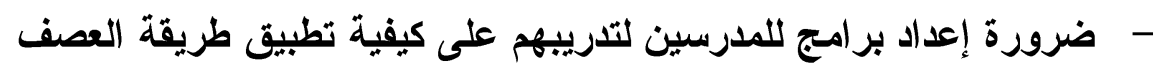
الذهني، وكنلك كيفية وضع الخطط لتطبيقها في التدريس.

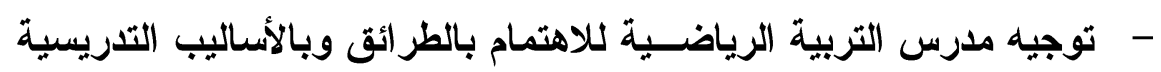

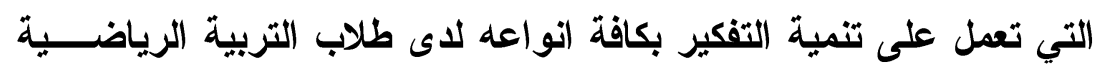
التي قد تكون في تنميتها فائدة لإزالة المعوقات التي يواجهية لتعها الطلبة خلال المراحل الدراسية المختلفة. أكساب المهارات لمختلف المسابقات الرياضية في ظل نظامنا التعليمي

- $१$ - Website: http://www.bsu.edu.eg/Sector_Home.aspx?cat_id=13\# E-mail: journal.science@uahoo.com 


\section{1 \\ أوب: المصادر العرببة:}

ا إبراهيم عبـــ الســتار : آفاق جديدة في دراسة الابداع، وكالة المطبوعات، الكويت.

(1 $9 \vee \wedge)$

r أحمد عبد اللطيف عبادة : "أســلوب العصـف الذهني والحلول الابتكارية للمشكلات"،

مركز الخليج العربي للبحوث التربوية، الكويت.

(199r)

: التفكير " العصف الذهني "، كلية المعلمين، في الباحة.

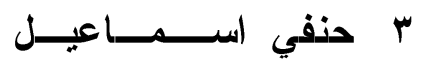

محمد(r..r. (r.

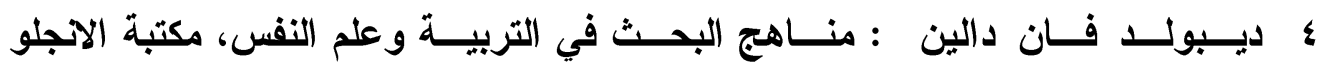
المصرية، طب، القاهرة.

(19^0)

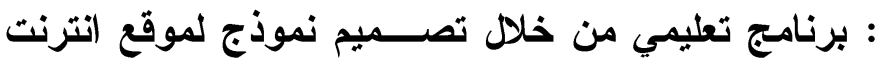

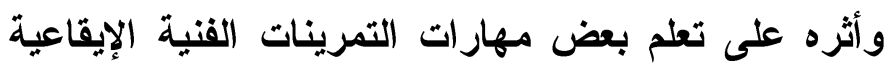

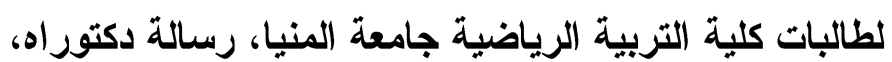

غير منشورة، كلية التربية الرياضية، جامبة جامعة الرية المنيا.

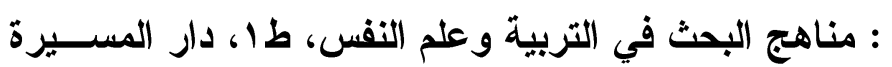
للنشر والتوزيع والطباعة، عمان، الأردن.

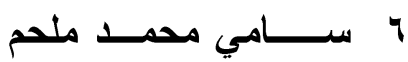
$(r . .$.

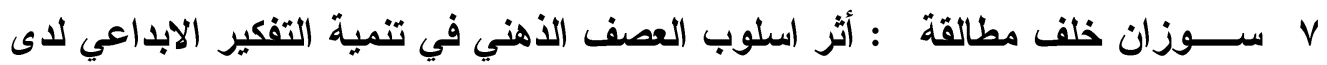

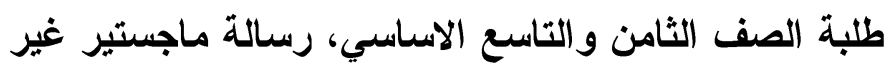
منشورة، جامعة اليرموك، كلية التربية والفنون، الاردن. : أثر طريقة العصف الذهني في التفكير الابداعي والتحصيل

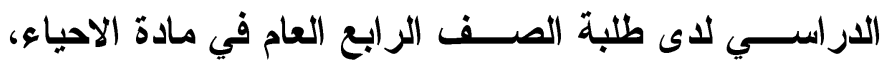

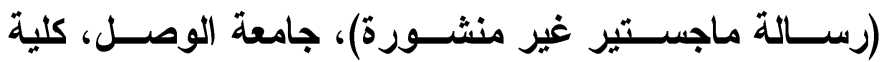

$$
\text { التربية. }
$$

9 و عزيز سمارة، وآخرون : مبـادئ القياس والتقويم في التربية، طץ، مكتبة دار الفكر

$$
\text { الثقافة للنشر والتوزيع، عمان، الاردن. }
$$

، : طرائق التدريس العامة، مكتبة الفلاح، الكويث.
^ عبد الســتار الاليمي $(r . .0)$

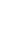


ا غســان ســـالم الايني : أثر الاســـاليـب التربويــة في التفكير الابداعي العراقي وعلاقته ببعض المتغيرات (اطروحة دكتور اه غير منشورة)

$$
\text { جامعة بغداد، كلية الآداب. }
$$

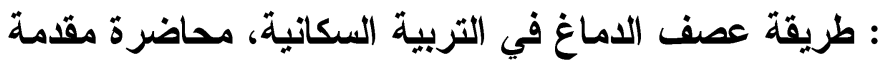

$$
\text { الى ندوة التربية السكانية، دمشث (غيل عنيل منشورة). }
$$

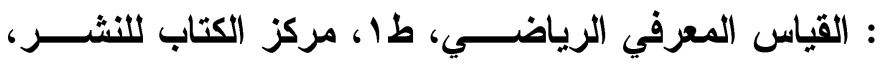

$$
\text { القاهرة، مصر. }
$$

: " تصميم نموذجين تعليميين لمادة طرائق التدريس وأثرهما في التحصيل الدراسي والتفكير العلمي ودافعية التعلم و الأكاء

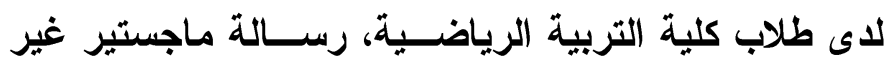
منشورة، جامعة الوصل، كلية التربية الرياضية.

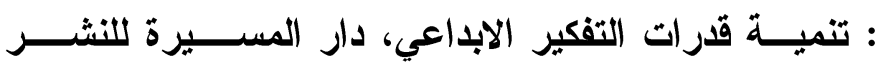

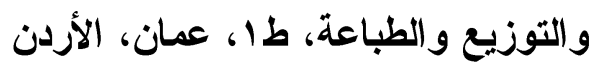

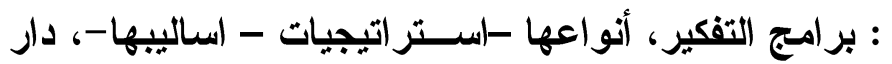
العلم للطباعة و النشر ، كلية التربية جامعة الموصل. 10 $(r .1)$

17 محمد ياســين وهيب،

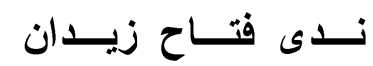
$(r .1)$

V مركز التدريب التربوي : اسلوب العصف الذهني، وادي الدواسر، العراق.

$$
(r . r)
$$

: أثر العصــف الأهني في تنمية التفكير العلمي والتحصــيل

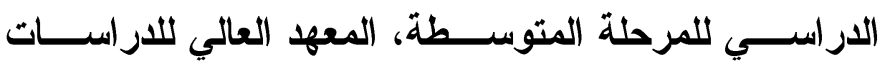
1) هنــاء محمد صــالح $(r \cdot . \varepsilon)$

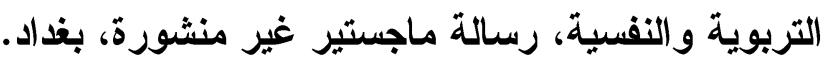

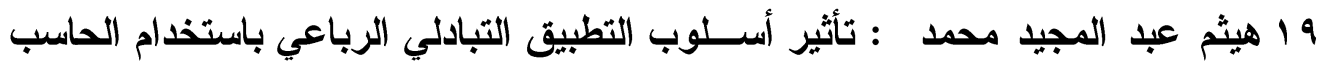

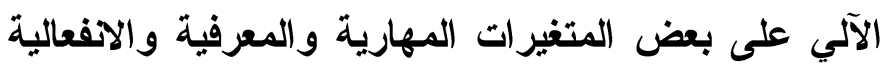
$(r . .0)$

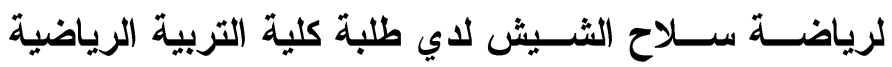

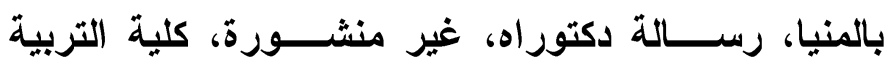

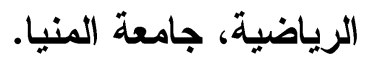
ثانيا: المصادر الأجنبـية:

20 Guilford ، j.p‘(1976) : The nature of human intelligence 'ms gawkily book company 'new York.

- 1 - Website: http://www.bsu.edu.eg/Sector_Home.aspx?cat_id=13\# E-mail: journal.science@uahoo.com 


\section{ملنمر البحث}

أثر استنفدام أسلوب العصف الذهني على تعلم المهارات الأساسية في

الكرة الطائرة لدي تلاميذ المرهلة الابتندائية

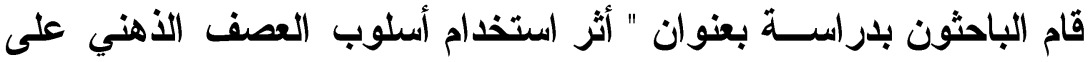

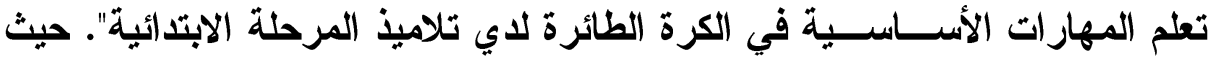

هاف البحث إلى التعرف على تأثير اســتراتيجية العصف الذهني في تعلم المهارات الاســــية للكرة الطائرة لاى تلاميذ الصف السادس الابتدائي المرحلة الابتدائية؛

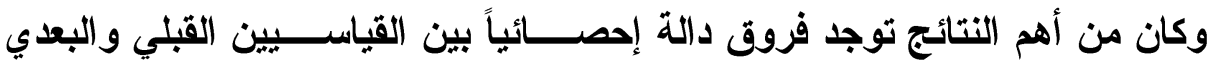
للمجموعة الضــابطة لصالح القياس البعدي في مستوى المهار ات الأساسية للكرة

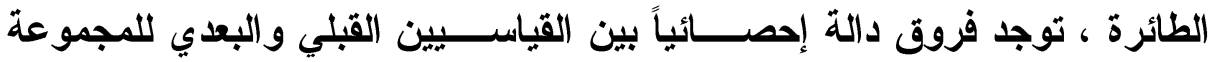
التجريبية لصـالح القياس البعدي في مســتوى المهارات الأساسية للكرة الطائرة ، توجد فروق دالة إحصائياً بين القياسيين البعديين للمجموعتين الضابطة والتجريبية لصـالح القياس البعدي للمجموعة التجريبية في مستوى المهارات الأساسية للكرة

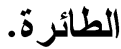

\section{Abstract}

Researchers study entitled "Brainstorming Strategy and its impact in learning volleyball basic skills for Primary school students" Where the aim of the research is to identify the impact in learning volleyball basic skills for Primary school students; and it was the most important results There are significant differences between compiling the pre and post to the control group in favor of the dimensional measurement in the learning volleyball basic skills level. There are significant differences between pre and post compiling the experimental group in favor of the dimensional measurement in the learning volleyball basic skills level. There are significant differences between the two groups in post compiling control and experimental favor telemetric experimental group in the learning volleyball basic skills level. 